Microscopy

\section{Coming Events}

2017

International Frontiers of Electron Microscopy in Materials Science

September 10-15, 2017

Johannesburg, South Africa

http://femms2017.org

CIASEM 2017

September 25-29, 2017

Varadero Beach, Cuba

www.ciasem2017.sld.cu

MS\&T17: Materials Science \& Technology October 8-12, 2017

Pittsburgh, PA

www.matscitech.org

American Vacuum Society

October 29-November 3, 2017

Tampa, FL

www.avs.org

Testing and Failure Analysis

November 5-9, 2017

Pasadena, $\mathrm{CA}$

www.asminternational.org/web/istfa-2017/home

Neuroscience 2017

November 11-15, 2017

Washington, DC

www.sfn.org

\section{MRS Fall Meeting}

November 26-December 1, 2017

Boston, MA

www.mrs.org/fall2017

American Society for Cell Biology

December 2-6, 2017

Philadelphia, PA

http://ascb.org/future-ascb-annual-meetings

\section{8}

Microscopy \& Microanalysis 2018

August 5-9, 2018

Baltimore, MD

www.microscopy.org

\section{9}

Microscopy \& Microanalysis 2019

August 4-8, 2019

Portland, OR

www.microscopy.org

\section{0}

Microscopy \& Microanalysis 2020

August 2-6, 2020

Milwaukee, W

www.microscopy.org

2021

Microscopy \& Microanalysis 2021

August 1-5, 2021

Pittsburgh, PA

www.microscopy.org

\section{2}

Microscopy \& Microanalysis 2022

July 31-August 4, 2022

Portland, OR

www.microscopy.org

More Meetings and Courses

Check the complete calendar near the back of this magazine.

\title{
Developing a Bigger Palette to Elucidate Intricate Biologic Interactions
}

\author{
Stephen W. Carmichael \\ Mayo Clinic, Rochester, MN 55905 \\ carmichael.stephen@mayo.edu
}

Fluorescence microscopy has proven to be a valuable method to localize molecules of biologic interest. However, the nature of broad fluorescence spectra limits the number of resolvable colors to about 5 (or with complicated instrumentation and analysis up to 9). Stimulated Raman scattering (SRS) microscopy avoids this limitation and provides peaks about 100 times narrower than fluorescence by relying on the interaction between the vibrational motion from the chemical bonds in the molecule of interest and laser beams. Lu Wei, Wei Min, and their colleagues have developed a methodology and an assortment of dyes to create a palette of 24 resolvable colors, with the potential for further expansion [1].

In SRS microscopy two laser beams (referred to as Stokes photons and pump photons) with different energies are collinearly focused onto cell samples. When the energy differences between the two beams matches the vibrational frequency of the targeted chemical bonds, the chemical bonds are efficiently excited to the vibrational excited state. A method to detect the intensity loss of the pump beam was used to spatially and temporally resolve molecules with selected chemical bonds. All previous SRS imaging is in the non-resonance region where the laser wavelengths are far away from molecular absorptions and thus have inadequate sensitivity for general applicability. Wei et al. exploited and determined a special region by carefully adjusting the two laser beams to be close to the electronic absorption of the molecules that could obtain signal enhancement with optimal contrast between vibrational signal and electronic background. They termed this electronic pre-resonance SRS (epr-SRS). Combining epr-SRS with selected dyes provided an improvement in sensitivity of about 1,000 over other non-resonance SRS imaging, which was comparable to confocal fluorescence microscopy, while retaining distinct vibrational contrast.

Wei et al. created a palette of triple-bond-conjugated (with, for example, alkynes) near-infrared dyes. Each displays a single peak in the Raman spectral window where background noise is non-existent (cell-silent). Combining this palette with available fluorescent probes provided 24 resolvable colors. They called this super-multiplex vibrational imaging.

Proof-of-principle experiments on both fixed and living cells demonstrated several successful applications. For example, imaging of proteome turnover dynamics

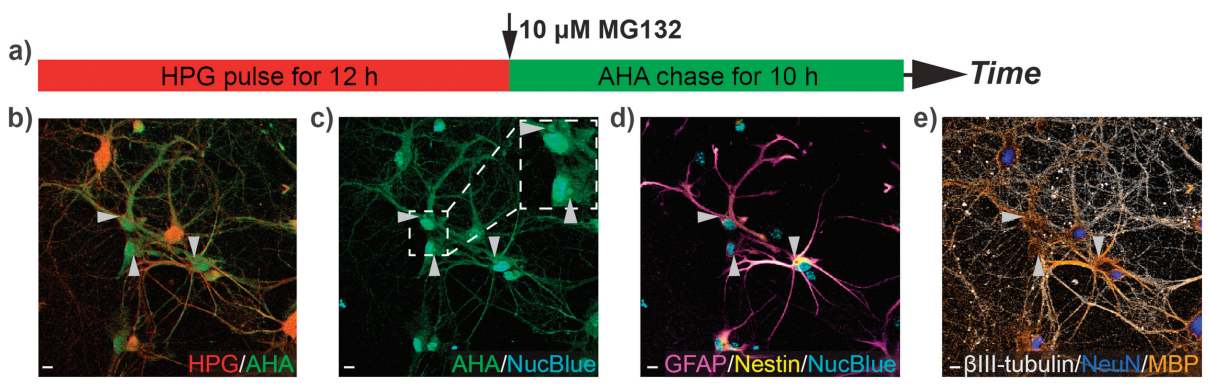

Figure 1: Super-multiplex optical imaging for investigation of proteome turnover dynamics in hippocampal neuronal cultures. (a) Pulse-chase (HPG-AHA) experimental design. MG132: proteasome inhibitor. (b-e) Cytosolic aggregations (indicated by arrowheads) are mostly from proteins synthesized in the chase period (b-c) and appear mostly in astrocytes (d) but not in neurons (e). HPG: 1-homopropargylglyceine. AHA: 1-azidohomoalanine. GFAP: glial fibrillary acidic protein. MBP: myelin basic protein. Scale bars $=10 \mu \mathrm{m}$. 




Fast TEM Imaging for Life Sciences

\section{Ideal Magnification Factors for TEM Imaging}

-12,16, and 29 Megapixel Scientific Sensors

- Focus Friendly Readout Speeds

- Low Maintenance Modular Design

- High Performance Lens

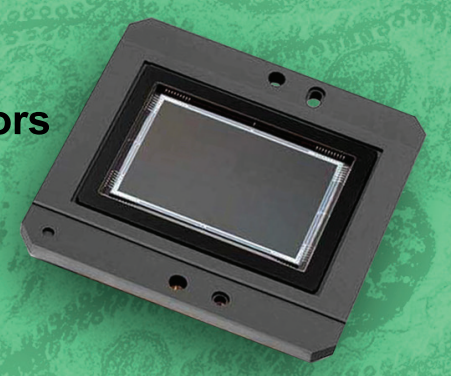

Over 2000 AMT Systems worldwide operate with fast and reliable service and support!

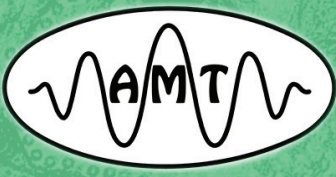

\section{Advanced Microscopy Techniques}

242 West Cummings Park, Woburn, MA 01801

Tel: (978)774-5550 - Fax: (978)739-4313

sales@amtimaging.com

www.amtimaging.com 
in hippocampal neuronal cultures demonstrated that misfolded proteins were sequestered within inclusions in astrocytes rather than neurons (Figure 1). This may serve a protective function by sequestering potentially harmful proteins. This in turn suggests that the astrocyte resistance that has been observed previously could be due to their ability to actively form protein inclusions that isolate toxic proteins, something neurons are unable to do.

These and other studies demonstrated improved sensitivity, resolution, labeling versatility, and biocompatibility that complement fluorescence microscopy. In addition, Wei et al. suggested that their technique can be further improved in at least 3 ways. First, the dye palette could potentially be expanded to 50 or more colors by filling the rather broad cell-silent window with individual sharp peaks from new vibrational moieties. Secondly, genetically encoded infrared proteins could be engineered to serve as vibrational reporters. Third, techniques (such as hyper-spectral imaging) could be implemented to realize faster and simultaneous signal acquisition. Because of all the improvements and potential improvements in the 24-color (super-multiplex) optical imaging approach developed by Wei et al., we can expect this new technology to find wide application in the probing of complex biologic systems.

\section{References}

[1] L Wei et al., Nature 544 (2017) 465-70.

[2] The author gratefully acknowledges Drs. Lu Wei and Wei Min for reviewing this article.

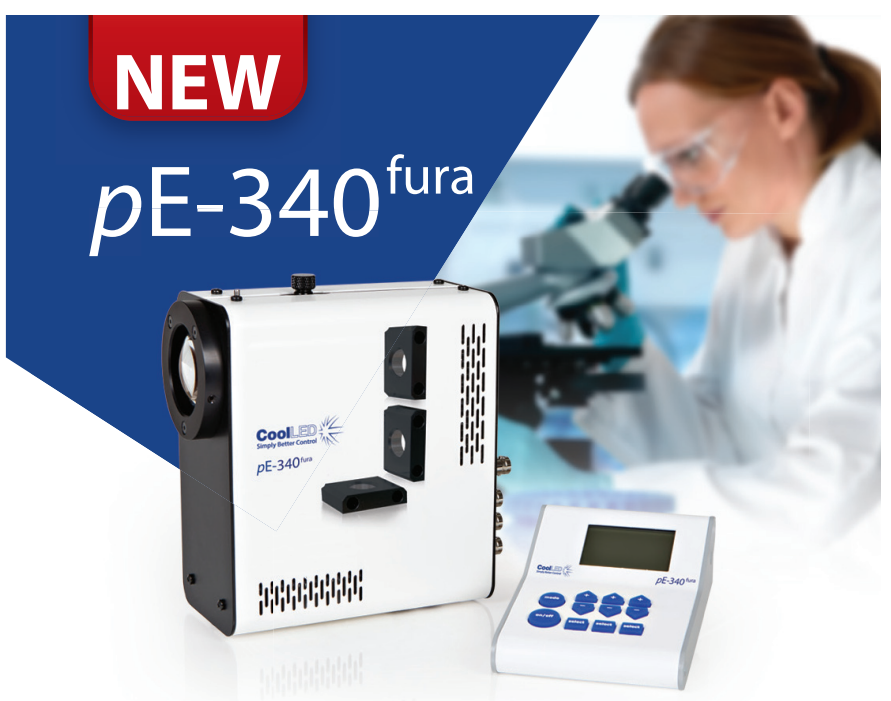

NEW Fast, Controllable LED Illumination for Fura-2 Ratiometric Calcium Imaging
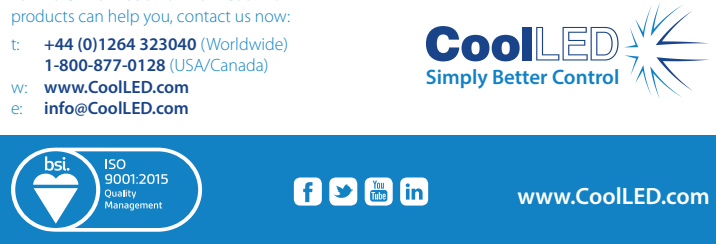
MT

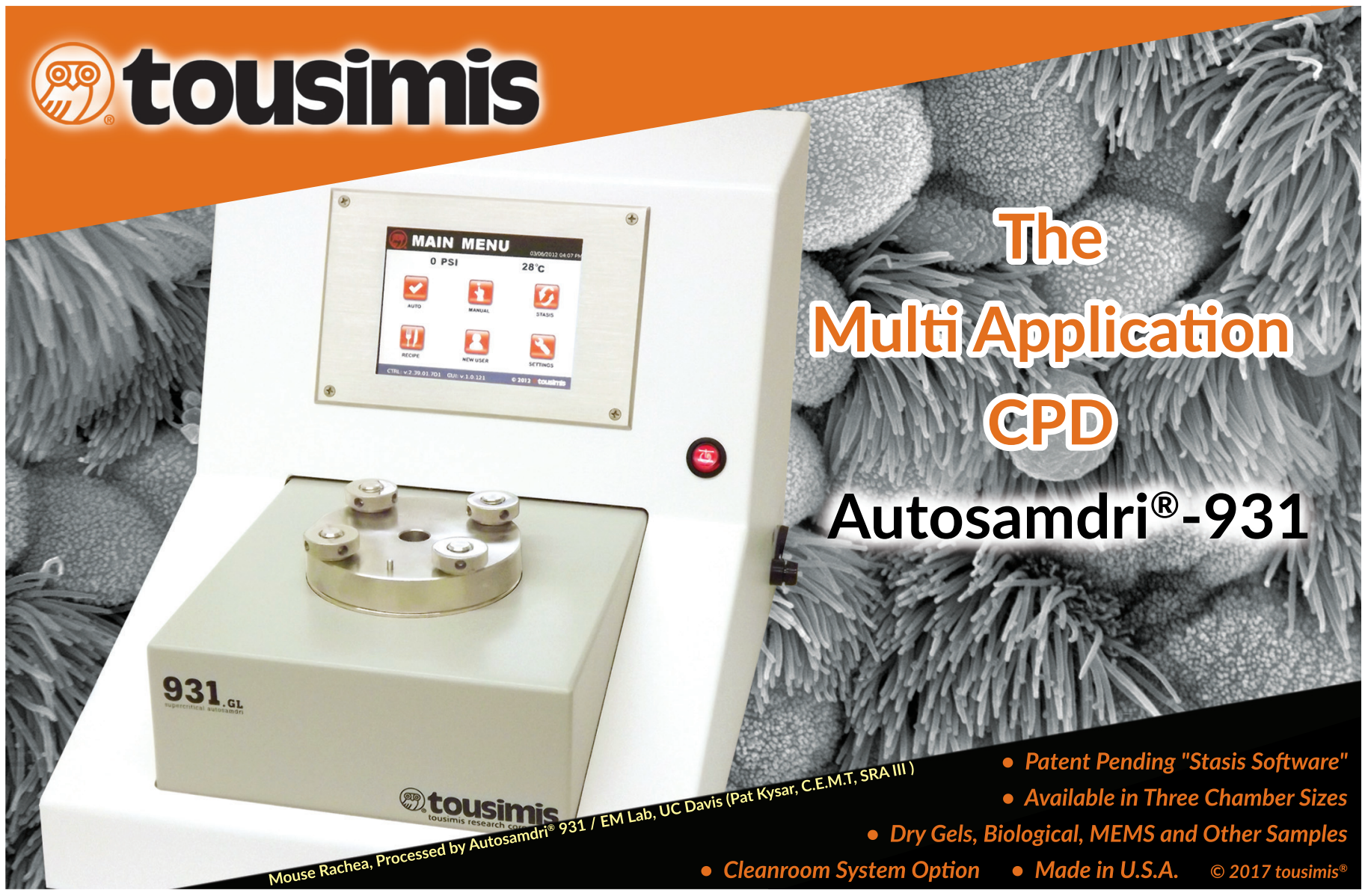


